\title{
Occurrence of enterococci in mastitic cow's milk and their antimicrobial resistance
}

\author{
Hanna Różańska ${ }^{1}$, Aleksandra Lewtak-Piłat ${ }^{2}$, \\ Maria Kubajka ${ }^{1}$, Marcin Weiner ${ }^{1}$ \\ ${ }^{1}$ Department of Microbiology, ${ }^{2}$ Department of Hygiene of Food of Animal Origin, \\ National Veterinary Research Institute, 24-100 Puławy, Poland \\ bruna@piwet.pulawy.p1
}

Received: July 11, 2018

Accepted: February 21, 2019

\begin{abstract}
Introduction: The aim of the study was to evaluate the occurrence of enterococci in inflammatory secretions from mastitic bovine udders and to assess their antimicrobial resistance. Material and Methods: A total of 2,000 mastitic milk samples from cows were tested in 2014-2017. The isolation of enterococci was performed by precultivation in buffered peptone water, selective multiplication in a broth with sodium azide and cristal violet, and cultivation on Slanetz and Bartley agar. The identification of enterococci was carried out using Api rapid ID 32 strep kits. The antimicrobial susceptibility was evaluated using the MIC technique. Results: Enterococci were isolated from 426 samples (21.3\%). Enterococcus faecalis was the predominant species (360 strains), followed by E. faecium (35 isolates), and small numbers of others. The highest level of resistance was observed to lincomycin, tetracycline, quinupristin/dalfopristin (Synercid), erythromycin, kanamycin, streptomycin, chloramphenicol, and tylosin. Single strains were resistant to vancomycin and ciprofloxacin. All isolates were sensitive to daptomycin. E. faecalis presented a higher level of resistance in comparison to E. faecium, except to nitrofurantoin. Conclusion: The results showed frequent occurrence of enterococci in mastitic cow's milk and confirmed the high rate of their antimicrobial resistance.
\end{abstract}

Keywords: cows, mastitis, Enterococcus spp., occurrence, antimicrobial resistance.

\section{Introduction}

Udder inflammations (mastitis) are the most frequent and cost-generating illness of dairy cows all over the world $(1-3,9,17,20,21,25,26,28,29)$. Many different microorganisms can infect the mammary gland. Due to their different aetiology and epidemiology, contagious and environmental cases of mastitis are distinguished $(1,4,9,20,26,27)$. Streptococci are mainly responsible for contagious mastitis. Enterococci are one of the environmental causative agents of mastitis. These opportunistic bacteria are a part of normal physiological gut flora in humans and animals, but over last years they have become one of the main pathogens causing numerous infections in humans, mainly those hospital-acquired, such as bacteraemia and infections of the urinary tract, skin, soft tissue, abdomen and pelvis, and central nervous system. These infections are caused mainly by E. faecalis (about $80.0 \%$ ) and E. faecium $(10.0 \%-$
$15.0 \%)(3,6,14,16,19,22,31)$. The high tolerance of enterococci to disadvantageous conditions allows for their long survival in the environment, including in abattoirs. For this reason, potential infections of the mammary gland are easy and simple. Enterococci are characterised by a high level of resistance to many antibacterial substances, both by intrinsic and acquired mechanisms. Due to their ability to acquire and transfer resistance-determining genes to other bacteria, they are perceived as a good indicator of antimicrobial resistance in the environment $(15,20,22)$. Another matter of concern is the possibility of the transmission of enterococci from the inflamed udder to humans. The growing consumption of raw, unpasteurised milk and products produced from this milk seems to indicate that there is a possibility of transfer of potentially pathogenic and antimicrobial-resistant enterococci to humans via the food chain. $(1,3,6,8,13,15,22,24$, $28,31,32)$. There are no sufficient data from Poland about the occurrence of Enterococcus spp. in mastitic 
cow's milk or about their susceptibility to antimicrobials. For this reason, this investigation was undertaken to evaluate the occurrence of enterococci in milk of cows with clinical and subclinical mastitis and to assess their antimicrobial resistance.

\section{Material and Methods}

In total, 2,000 milk samples were taken by physicians from individual cows suspected of mastitis. The samples were collected in different parts of Poland and were sent to our laboratory under temperaturecontrolled conditions. The samples were frozen until analysis. To isolate enterococci, $1 \mathrm{ml}$ of the sample was incubated in buffered peptone water overnight at $37 \pm 1^{\circ} \mathrm{C}$. Then, $100 \mu \mathrm{L}$ of the culture was transferred into a broth with sodium azide and crystal violet (azide dextrose broth supplemented with $1.6 \%$ bromocresol purple and $1.3 \mathrm{~mL} / \mathrm{L}$ crystal violet, Merck, Germany). After incubation $\left(24 \mathrm{~h}\right.$ at $\left.37^{\circ} \mathrm{C}\right)$, one loop $(10 \mu \mathrm{L})$ of the culture was spread on the surface of Slanetz and Bartley agar (Oxoid, UK) and incubated overnight at $37^{\circ} \mathrm{C}$. The suspected colonies were identified using the API rapid ID 32 STREP kit (bioMérieux, France) following the manufacturer's instructions. The antimicrobial resistance of the confirmed Enterococcus isolates was evaluated using the minimum inhibitory concentration (MIC) technique (in Sensititre CMV3AGPF NARMS Plates, Trek Diagnostic Systems, UK) with decreasing levels of tigecycline (TGC), tetracycline (TET), chloramphenicol (CHL), daptomycin (DAP), streptomycin (STR), tylosin tartrate (TYLT), quinupristin/dalfopristin (SYN), linezolid (LZD), nitrofurantoin (NIT), penicillin (PEN), kanamycin (KAN), erythromycin (ERY), ciprofloxacin (CIP), vancomycin (VAN), lincomycin (LIN), and gentamycin (GEN). All investigations were performed with a Sensititre Autoreader device (Trek, UK). The reference E. faecalis ATCC 29212 strain was used as a control. The results were interpreted automatically, according to CLSI standards. For comparison of the resistance to each substance possessed by $E$. faecalis and E. faecium, the $\mathrm{Z}$ test for two independent proportions was used. For trends evaluation, the mobile means method was applied.

\section{Results}

Enterococcus spp. bacteria were isolated from 426 samples $(21.3 \%)$. In this number, 360 isolates were identified as Enterococcus faecalis and 35 as E. faecium. A small number of isolated specimens were identified as E. hirae, E. casseliflavus, E. durans, and E. avium. They were not included in the result analysis. The results of antimicrobial resistance of the isolated Enterococcus spp., E. faecalis, and E. faecium strains are summarised in Table 1 and Fig. 1. The highest Enterococcus spp. resistance was to lincomycin $(82.16 \%)$, followed by tetracycline $(61.5 \%)$, Synercid (60.8\%), erythromycin (48.83\%), kanamycin (47.42\%), streptomycin $(46.48 \%)$, chloramphenicol $(44.83 \%)$, and tylosin $(42.49 \%)$. The lowest rates of resistance were to vancomycin and ciprofloxacin (0.94 and 0.47\%, respectively). All strains were sensitive to daptomycin. As shown in Table 1 and Fig. 1, significant differences in resistance between E. faecalis and E. faecium were observed, especially to chloramphenicol, erythromycin, nitrofurantoin, quinupristin/dalfopristin (Synercid), streptomycin, and tetracycline. In total, the isolates of E. faecium presented lower resistance than E. faecalis, except to nitrofurantoin.

Table 1. Antimicrobial resistance of enterococci isolated from mastitic cow's milk $(n=2,000)$

\begin{tabular}{|c|c|c|c|}
\hline \multirow[b]{2}{*}{ Antimicrobials } & \multicolumn{3}{|c|}{ Number $\%$ of resistant strains } \\
\hline & $\begin{array}{l}\text { Enterococcus spp. } \\
(\mathrm{n}=426)\end{array}$ & $\begin{array}{l}\text { Enterococcus faecalis } \\
(\mathrm{n}=360)\end{array}$ & $\begin{array}{l}\text { Enterococcus faecium } \\
(\mathrm{n}=35)\end{array}$ \\
\hline Chloramphenicol (CHL) & $191 / 44.84$ & $173 / 49.43$ & $7 / 20.0$ \\
\hline Ciprofloxacin (CIP) & $2 / 0.47$ & $2 / 0.57$ & $1 / 2.86$ \\
\hline Daptomycin (DAP) & 0 & 0 & 0 \\
\hline Erythromycin (ERY) & $208 / 48.83$ & $177 / 50.57$ & $11 / 31.43$ \\
\hline Gentamicin (GEN) & $47 / 11.03$ & $31 / 8.86$ & $2 / 5.71$ \\
\hline Kanamycin (KAN) & $202 / 47.42$ & $196 / 56.0$ & $15 / 42.86$ \\
\hline Linkomycin (LIN) & $350 / 82.16$ & $294 / 84.0$ & $25 / 71.43$ \\
\hline Linezolid (LZD) & $15 / 3.52$ & $14 / 4.0$ & $1 / 2.86$ \\
\hline Nitrofurantoin (NIT) & $27 / 6.34$ & $17 / 4.86$ & $13 / 37.14$ \\
\hline Penicillin (PEN) & $11 / 2.58$ & $12 / 3.43$ & $2 / 5.71$ \\
\hline Qunupristin/dalfopristin (SYN) & $259 / 60.8$ & $296 / 84.57$ & $15 / 42.86$ \\
\hline Streptomycin (STR) & $198 / 46.48$ & $167 / 47.71$ & $10 / 28.57$ \\
\hline Tetracycline (TET) & $262 / 61.5$ & $287 / 82.0$ & $11 / 31.43$ \\
\hline Tigecycline (TGC) & $5 / 1.17$ & $4 / 1.14$ & 0 \\
\hline Tylosin (TYLT) & $181 / 42.49$ & $170 / 48.57$ & $11 / 31.43$ \\
\hline Vancomycin (VAN) & $4 / 0.94$ & $3 / 0.86$ & $1 / 2.86$ \\
\hline
\end{tabular}


The antimicrobial resistance trends of E. faecalis isolated in 2014-2017 are shown in Table 2 and Fig. 2. Because of the low number of E. faecium isolates, the trends for this species were not analysed. The presented data indicate some differences between the years, especially for chloramphenicol, erythromycin, lincomycin, streptomycin, tetracycline, and tylosin, for which a decrease in resistance was observed. On the basis of the results, 53 resistance profiles were established. In total, 193 E. faecalis strains (45.31\%) were resistant to at least three substances from three different groups (multiresistant strains).

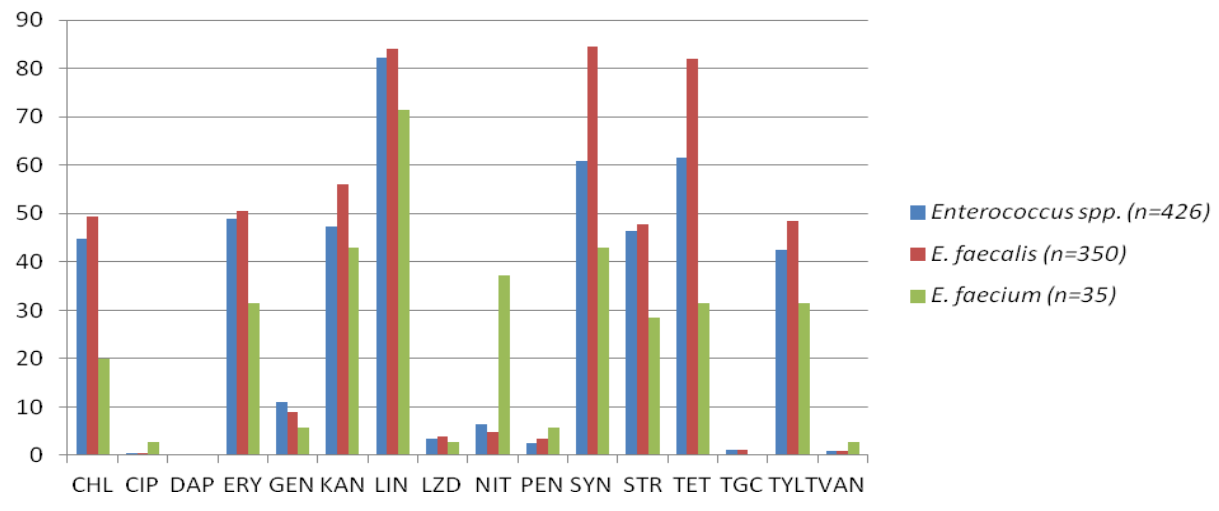

Fig. 1. Comparison of the antimicrobial resistance of enterococci isolated from mastitic milk samples. For antibiotic abbreviations see Table 1

Table 2. Trends in antimicrobial resistance of Enterococcus faecalis in 2014-2017

\begin{tabular}{|c|c|c|c|c|c|}
\hline \multirow[b]{2}{*}{ Antimicrobials } & \multicolumn{5}{|c|}{ Number $\%$ of resistant strains } \\
\hline & $\begin{array}{l}\text { Total } \\
(\mathrm{n}=360)\end{array}$ & $\begin{array}{l}2014 \\
(n=127)\end{array}$ & $\begin{array}{l}2015 \\
(n=64)\end{array}$ & $\begin{array}{l}2016 \\
(n=90)\end{array}$ & $\begin{array}{l}2017 \\
(n=79)\end{array}$ \\
\hline Chloramphenicol (CHL) & $173 / 49.43$ & $89 / 70.08$ & $27 / 42.19$ & $31 / 34.44$ & $26 / 32.91$ \\
\hline Ciprofloxacin (CIP) & $2 / 0.57$ & 0 & 0 & $1 / 1.11$ & $1 / 1.27$ \\
\hline Daptomycin (DAP) & 0 & 0 & 0 & 0 & 0 \\
\hline Erythromycin (ERY) & $177 / 50.57$ & $92 / 72.44$ & $29 / 45.31$ & $29 / 32.22$ & $27 / 34.18$ \\
\hline Gentamicin (GEN) & $31 / 8.86$ & $4 / 3.15$ & $8 / 12.5$ & $10 / 11.11$ & 9/11.39 \\
\hline Kanamycin (KAN) & $196 / 56.0$ & $90 / 70.87$ & $35 / 54.69$ & $37 / 41.11$ & $34 / 43.04$ \\
\hline Linkomycin (LIN) & $294 / 84.0$ & $116 / 91.34$ & $44 / 68.75$ & $71 / 78.89$ & $63 / 79.75$ \\
\hline Linezolid (LZD) & $14 / 4.0$ & $2 / 1.57$ & $8 / 12.5$ & $3 / 3.33$ & $1 / 1.27$ \\
\hline Nitrofurantoin (NIT) & $17 / 4.86$ & $2 / 1.57$ & $8 / 12.5$ & $4 / 4.44$ & $3 / 3.8$ \\
\hline Penicillin (PEN) & $12 / / 3.43$ & $6 / 4.72$ & $1 / 1.56$ & $2 / 2.22$ & $3 / 3.8$ \\
\hline Qunupristin/dalfopristin (SYN) & $296 / 84.57$ & $106 / 83.46$ & $42 / 65.63$ & $81 / 90.0$ & $67 / 84.81$ \\
\hline Streptomycin (STR) & $167 / 47.71$ & $89 / 70.08$ & $19 / 29.69$ & $31 / 34.44$ & $28 / 35.44$ \\
\hline Tetracycline (TET) & $287 / 82.0$ & $111 / 87.4$ & $42 / 65.63$ & $71 / 78.89$ & $63 / 79.75$ \\
\hline Tigecycline (TGC) & $4 / 1.14$ & $2 / 1.57$ & $1 / 1.56$ & $1 / 1.11$ & 0 \\
\hline Tylosin (TYLT) & $170 / 48.57$ & $82 / 64.57$ & $27 / 42.19$ & $29 / 32.22$ & $32 / 40.51$ \\
\hline Vancomycin (VAN) & $3 / 0.86$ & $2 / 1.57$ & 0 & $1 / 1.11$ & 0 \\
\hline
\end{tabular}

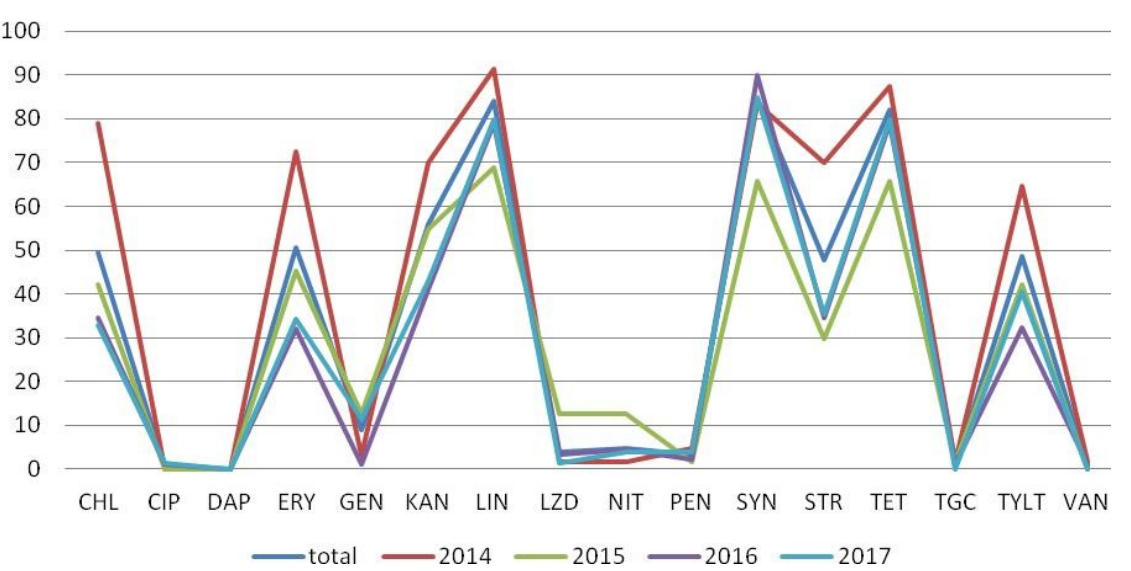

Fig. 2. Trends in antibacterial resistance of E. faecalis in 2014-2017

For antibiotic abbreviations see Table 2 


\section{Discussion}

Opinions concerning the occurrence of enterococci in mastitic cow's milk vary. Some authors indicate a rare occurrence of enterococci in mastitic milk samples. Petersson-Wolfe et al. (28) showed 0.3\% to $1.3 \%$ prevalence in milk samples from cows with subclinical mastitis in Sweden. Botrel et al. (2) isolated these bacteria in $2.4 \%$ of milk samples from cows with clinical mastitis and $3.1 \%$ in subclinical cases in France. Similar findings were reported by Gürler et al. (15) who isolated Enterococcus spp. in $3.26 \%$ of milk samples from subclinically mastitic cows in Turkey. Concurring results were described by other authors in Sudan (11), Slovakia (18), and Poland (24). In contrast, Kuyucouglu et al. (23) isolated enterococci from $10.9 \%$ of mastitic milk samples in Turkey. Our results are much more similar to those reported by three groups: Cameron et al. (5) who recovered enterococci from $15.25 \%$ of samples tested in Canada; Cervinkova et al. (7) who isolated these bacteria in $16.1 \%$ of samples in the Czech Republic; and Kateete et al. (21) who isolated enterococci in $19.5 \%$ of samples in Uganda. According to Hamzah et al. (17), enterococci were present in $60.0 \%$ of mastitic milk samples collected in Iraq. The cited data showed enterococci diversity in mastitic milk samples depending on geographical region and animal production specifics in different countries. In our experiments, E. faecalis was the predominant species, similar to the results presented by Cameron et al. (5), Kunyucouglu et al. (23), and Hamzah et al. (17). In studies performed by Kateete et al. (21), E. faecium was most often isolated, whereas Klimiene et al. (22) pointed to E. durans as the predominant strain in Lithuania.

Enterococci exploit several mechanisms of intrinsic and acquired resistance to antimicrobials. The intrinsic resistance concerns $\beta$-lactams, cephalosporins, clindamycin, and low concentrations of aminoglycosides, whereas the acquired one reduces susceptibility to tetracyclines, ciprofloxacin, erythromycin, linezolid, daptomycin, quinupristin/ dalfopristin, and vancomycin $(8,15)$. This regularity, described by many authors, seems to be partially confirmed in our results. In general, almost all authors indicated a high level of antimicrobial resistance of enterococci; however, this level differs by species, substance, and country. The enterococci isolated from mastitic milk samples in Poland resisted these therapeutics to a greater extent than those from other countries.

According to the data presented in Table 1 and Fig.1, E. faecalis demonstrates a higher rate of resistance than E. faecium, except as it resists nitrofurantoin $(4.86 \%$ and $37.14 \%$, respectively). The data presented by other authors are not clear. According to Klimiene et al. (22), E. faecium showed higher resistance to $\beta$-lactams than $E$. faecalis. El Zubeir et al. (11) noted the wide range of resistance of enterococci to antimicrobials, especially to enrofloxacin, kanamycin, gentamicin, lincomycin, and oxacillin. According to Erbas et al. (12), 1.1\% of the isolates in Turkey showed resistance to vancomycin, $10.7 \%$ to chloramphenicol, $28.7 \%$ to erythromycin, and $81 . \%$ to tetracycline. Fabianova et al. (13) noted $4.5 \%$ of strains resistant to vancomycin, $2.1 \%$ to teicoplanin, $13.0 \%$ to erythromycin, $39.1 \%$ to gentamicin, $45.6 \%$ to tetracycline, and $93.5 \%$ to ampicillin. There are no data to which to compare the trends in antimicrobial resistance of enterococci in the analysed period (20142017). In our opinion, the obtained results (Table 2, Fig. 2) should only be treated as tentative because the samples were not taken in the same places each year. The frequent occurrence of antimicrobial-resistant enterococci in mastitic milk samples indicates a potential possibility of transfer of these bacteria to humans, especially when consuming unpasteurised milk because these bacteria are also isolated from healthy cows prior to exhibition of mastitis symptoms (7). Similar markers of pathogenicity and resistance were detected in strains isolated from food of animal origin and from humans $(6,8,10,11,13)$. Our results confirmed the frequent presence of the resistant enterococci in mastitic milk, which can be considered as a potential risk to humans.

Conflict of Interests Statement: The authors declare that there is no conflict of interests regarding the publication of this article.

Financial Disclosure Statement: This scientific work was financially supported by the National Veterinary Research Institute in Puławy.

Animal Rights Statement: The authors declare that the experiments on animals were conducted in accordance with the local Ethical laws and regulations as regards care and use of laboratory animals.

\section{References}

1. Barlow J.: Mastitis therapy and antimicrobial susceptibility: a multispecies review with a focus on antibiotic treatment of mastitis in dairy cattle. J Mammary Gland Biol Neoplasia 2011, 16, 383-407.

2. Botrel M.-A., Haenni M., Morignat E., Sulpice Ph., Madec J.-Y., Calavas D.: Distribution and antimicrobial resistance of clinical and subclinical mastitis pathogens in dairy cows in Rhône-Alpes, France. Foodborne Path Dis 2010, 7, 479-485.

3. Bradley A.J.: Bovine mastitis: an evolving disease. Vet J 2002, 164, 116-128.

4. Burmańczuk A., Kowalski C., Roliński Z., Zań R., Krasucka D.: Activity of $\beta$-lactam antibiotics against certain microorganisms which cause mastitis in cows. J Vet Res 2016, 60, 267-271.

5. Cameron M., Saab M., Heider L., McClure J.T., RodriguesLecompte J.C., Sanchez J.: Antimicrobial susceptibility patterns of environmental streptococci recovered from bovine milk samples in the Maritime province of Canada. Front Vet Sci 2016, 3, art. 79. Doi: 10.3389/fvets.2016.00079. 
6. Cariolato D., Andrighetto C., Lombardi A.: Occurrence of virulence factors and antibiotic resistances in Enterococcus faecalis and Enterococcus faecium collected from dairy and human samples in North Italy. Food Control, 2008, 19, 886-892.

7. Cervinkova D., Vlkova H., Borodacova I., Makovcova J., Babak V., Lorencova A., Vrtkova I., Marosevic D., Jaglic Z.: Prevalence of mastitis pathogens in milk from clinically healthy cows. Vet Med 2013, 58, 567-575.

8. Chajęcka-Wierzchowska W., Zadernowska A., ŁaniewskaTrokenheim Ł.: Antibiotic resistance of Enterococcus strains present in food. Kosmos 2017, 314, 1, 67-79.

9. Ebrahimi A., Nikookhah F., Nikpour S., Majiian F., Gholami M.: Isolation of streptococci from milk samples of normal, acute, and subclinical mastitis cows and determination of their antibiotic susceptibility patterns. Pak J Biol Sci 2008, 11, 148-150.

10. Economou V., Gousia P.: Agriculture and food animals as a source of antimicrobial-resistant bacteria. Infect Drug Resist 2015, 8, 49-61.

11. El Zubeir I.E.M., Kutzer P., El Owni O.A.O.: Frequencies and antibiotic susceptibility patterns of bacteria causing mastitis among cows and their environment in Khartoum State. Res J Microbiol 2006, 1, 101-109.

12. Erbas G., Parin U., Turkyilmaz S., Ucan N., Oztruk M., Kaya O.: Distribution of antibiotic resistance genes in Enterococcus spp. isolated from mastitis bovine milk. Acta Vet Beograd 2016, 66, 336-346.

13. Fabianová J., Ducková V., Čročko M.: Presence of enterococci in cow milk and their antibiotic resistance. Potravinárstwo 2010, $4,17-21$.

14. Galal Abdel Hammeed K., Sender G., Korwin-Kossakowska A.: Public health hazard due to mastitis in dairy cows. Anim Sci Pap Rec 2006, 25, 2, 73-85.

15. Gürler H., Findik A., Gültiken N., Ay S.S., Çíftçí A., Koldaş E., Arslan S., Findik M.: Investigation on the etiology of subclinical mastitis in jersey and hybrid-jersey dairy cows. Acta Vet Beograd, 2015, 65, 358-370.

16. Hammerum A.M., Lester C.H., Heuer O.E.: Antimicrobialresistant enterococci in animals and meat: a human health hazard? Foodborne Path Dis 2010, 7, 1137-1148.

17. Hamzah A.M., Kadim H.K.: Isolation and identification of Enterococcus faecalis from cow milk samples and vaginal swab from human. Entomol Zool Sci 2018, 6, 218-222.

18. Idriss S.H.E., Foltys V., Tančin V., Kirchnerová K., Tančinová D., Zaujec K.: Mastitis pathogens and their resistance against antimicrobial agents in dairy cows in Nitra, Slovakia. Slovak J Anim Sci 2014, 47, 33-38.

19. Jackson C.R., Lombard J.E., Dargatz D.A., Fedorka-Cray P.J. Prevalence and antimicrobial resistance of enterococci isolated from US dairy cattle. Lett Appl Microbiol 2010, 52, 41-48.
20. Kagkli D.M., Vancanneyt M., Vandamme P., Hill C., Cogan T.M.: Contamination of milk by enterococci and coliforms from bovine faeces. J Appl Microbiol 2007, 103, 1393-1405.

21. Kateete D.P., Kabugo U., Baluku H., Nyakarahuka L., Kyobe S., Okee M., Najjuka Ch.F., Jaloba M.L.: Prevalence of antimicrobial susceptibility patterns of bacteria from milkmen and cows with clinical mastitis in and around Kampala, Uganda. PLOS ONE, 2013, 8, 5, e63413.

22. Klimienė I., Ružauskas M., Špakauskas V., Mockeliũnas R., Pereckienè A., Butrimaitè-Ambrozevičienè Č.: Prevalence of Gram-positive bacteria in cow mastitis and their susceptibility to beta-lactam antibiotics. Vet Med. Zoot 2011, 56, 65-72.

23. Kuyucouğlu Y.: Antibiotic resistances of enterococci isolated from bovine subclinical mastitis. Eurasian J Vet Sci 2011, 27, 231-234.

24. Malinowski E., Lassa H., Kłossowska A., Smulski S., Markiewicz H., Kaczmarowski M.: Etiological agents of dairy cows' mastitis in western part of Poland. Pol J Vet Sci 2006, 9, 191-194.

25. Oliver S.P., Murinda S.E.: Antimicrobial resistance of mastitis pathogens. Vet Clin North Am Food Anim Pract 2012, 28, 165185.

26. Overesch G., Stephan R., Perreten V.: Antimicrobial susceptibility of gram-positive udder pathogens from bovine mastitis milk in Switzerland. Schw Arch Tier 2013, 155, 339-350.

27. Persson Y., Nyman A.K., Grönlund-Andersson U.: Etiology and antimicrobial susceptibility of udder pathogens from cases of subclinical mastitis in dairy cows in Sweden. Acta Vet Scand 2011, 53, 36 http://www.actavetscand.com/content/53/1/36.

28. Petersson-Wolfe C.S., Currin J.: Environmental streptococci and Enterococcus spp.: a practical summary for controlling mastitis. 2012, www.ext.vt.edu.

29. Rocha B., Mendonca D., Niza-Ribeiro J.: Trends in antibacterial resistance of major bovine mastitis pathogens in Portugal. RCPV 2014, 109, 79-88.

30. Rüegsegger F., Ruf J., Tschour A., Sigrist Y., Rooskopf M., Hässig M.: Antimicrobial susceptibility of mastitis pathogens of dairy cows in Switzerland. Schw Arch Tier 2014, 156, 483-488.

31. Xiaohu W.U., Zhang Q., Ma Y., Zhang Y., Kan W., Zhao X.: Prevalence of virulence genes and resistance to antibiotics in pathogenic enterococci isolated from mastitic cows. J Vet Med. Sci 2016, 78, 1663-1683.

32. Zdolec N., Dobranić V., Butković I., Koturić A., Filipović I., Medvid V.: Antimicrobial susceptibility of milk bacteria from healthy and drug-treated cow udder. Vet Archiv 2016, 86, $163-172$. 